\title{
Florbela Espanca e Adília Lopes: A SUBVERSÃO DO PAPEL FEMININO
}

\section{Florbela Espanca and Adília Lopes: THE SUBVERSION OF FEMININE PAPER}

\section{Clêuma de Carvalho Magalhães ${ }^{1}$}

DOI: 10.11606/issn.1981-7169.crioula.2017.134886

RESUMO: Este trabalho tem como propósito analisar a subversão do papel feminino na obra das escritoras portuguesas Florbela Espanca e Adília Lopes. Cada uma à sua maneira, ambas constroem uma imagem feminina que foge aos padrões impostos pela sociedade portuguesa, negando o seu papel de submissão, assumindo o desejo que habita o seu corpo e afirmando-se como sujeito.

ABSTRACT: This article deals with the subversion of female paper in the works of Portuguese writers Florbela Espanca and Adília Lopes. Each writer in her own way, both construct a feminine image that escapes the standards imposed by Portuguese society, denying its role of submission, assuming the desire that inhabits her body and asserting herself as subject.

PALAVRAS-CHAVE: Florbela; Adília; Papel feminino; Subversão.

KEYWORDS: Florbela; Adília; Feminine paper; Subversion.

1 Doutoranda em História da Literatura, na Universidade Federal de Rio Grande FURG. Desenvolve a pesquisa intitulada Diálogos com a obra de Florbela Espanca: A recepção produtiva. 


\section{INTRODUÇÃO}

radicionalmente, o papel atribuído à mulher, seja no campo político, social, econômico e, principalmente, da sexualidade, tem sido de absoluta submissão. Vista como um ser inferior ao homem, sua voz foi silenciada durante séculos e, mesmo nos dias atuais, ainda são muitos os desafios que se impõem às conquistas femininas. Diante dessa realidade, afirmamos a importância da obra de autoras como Florbela Espanca e Adília Lopes. Distantes cronologicamente, pois a obra de Florbela Espanca veio a público nas primeiras décadas do século XX, iniciando-se com o Livro de Mágoas (1919), seguido pelo Livro de Sóror Saudade (1923) e pelo póstumo Charneca em Flor (1931), enquanto Adília Lopes adentra no cenário literário em 1985 com Um jogo bastante perigoso, e, portanto, inseridas em períodos histórico-literários diferentes, a produção poética das duas escritoras apresenta características bem distintas.

Enquanto Florbela Espanca elege o soneto como a forma poética para expressar toda a riqueza lírica que caracteriza os seus textos, Adília Lopes parece ignorar qualquer regra de composição, abusando da liberdade formal, "contaminando" os poemas com elementos tidos como a-poéticos, subvertendo a ideia do que é considerado lírico e rompendo com a expectativa do leitor tanto no que se refere à estrutura do texto como quanto ao sentido (des)construído por este. No entanto, Adília Lopes apresenta-se como uma leitora de Florbela Espanca, mantendo com a escritora alentejana um diálogo que resulta na produção de dois livros: Clube da poetisa morta (1997) e Florbela Espanca espanca (1999)2.

2 Em Dobra (cuja primeira edição é de 2009 e a segunda de 2014), a mais recente obra que reúne os livros de poesia de Adília, Florbela Espanca espanca (1999) tem o título al- 
Cumpre-nos destacar que em ambos os livros a presença de Florbela Espanca pode passar despercebida à maioria dos leitores e mesmo aqueles que a notem talvez experimentem a incômoda sensação de um "espancamento"3, de haver uma espécie de desconstrução da poesia florbeliana, (o que não causa grande surpresa aos leitores já familiarizados com a postura autoral de Adília Lopes). Há, no entanto, uma ligação entre as duas poetisas especialmente no tocante à construção do sujeito feminino que se apresenta na produção de ambas. Cada uma à sua maneira, elas dão voz à mulher e trazem à luz uma imagem feminina que desafia os padrões impostos pela sociedade portuguesa, negando o seu papel de submissão, assumindo o desejo que habita o seu corpo e afirmando-se como sujeito.

\section{FloRbELA EsPANCA: A EXPRESSÃo do DESEJO FEMININO}

Florbela Espanca vive num Portugal que passa por diversas transformações. Conhece a Monarquia decadente, o início da República, proclamada em cinco de outubro de 1910, e a repressão do Regime Ditatorial, que tem início em vinte e oito de maio de 1926.

O cenário político e cultural da época revela um país que, embora comece a respirar os ares da modernidade de um

terado para Versos verdes. Apesar de adotarmos a segunda edição de Dobra em nossas referências bibliográficas, manteremos o título original no corpo do texto, por julgarmos que assim é dada mais evidência à relação entre Adília Lopes e Florbela Espanca.

3 O termo "espancamento" é usado por Osvaldo Silvestre (2000), em "Adília Lopes espanca Florbela Espanca", ao explicar o procedimento de Adília Lopes com relação à autora de Charneca em flor. Trata-se do texto lido no lançamento de Florbela Espanca espanca, a 11 de Março de 2000, na Companhia de Teatro Sensurround, em Lisboa. 
novo século, ainda é uma nação em que vigora um regime conservador e repressivo, adepto de uma moral cristã marcada pelo preconceito e de um rígido sistema patriarcal que confere ao homem um forte poder sobre a mulher. No entanto, é nesse contexto que as escritoras começam a conquistar seu espaço. Não sem se depararem, obviamente, com a censura imposta pelo governo e com o desprezo e a ironia de muitos críticos e escritores desse período.

Embora ainda caracterizada pela leveza amorosa e por um exagerado sentimentalismo, a poesia escrita por mulheres começa a dar sinais de rebelião contra a imagem feminina que a tradição literária Ihes consagra: "a imagem dual conflitiva" (COELHO, 1994, p. 818) de anjo e demônio. Essa rebelião inicial, conforme Nelly Novaes Coelho (p. 818, grifo da autora), "se faz pelo desafio de assumir o lado mau, impuro dessa imagem... Isto é, não negaram o pecado, mas o assumiram com arrogância ou desafio. Ousaram o pecado da carne e o fizeram com volúpia, ainda que marcada por um inequívoco travo de culpa".

A poesia de Florbela Espanca, especialmente no Livro de Sóror Saudade e no Charneca em flor, constitui um claro exemplo dessa rebelião, pois seus versos subvertem o papel tradicionalmente atribuído à mulher, ou seja, o papel de objeto, de ser submisso e que deve silenciar diante da vontade masculina. Os poemas florbelianos libertam o ser feminino da clausura e deixam-no desfilar e emitir sua voz livremente, exercendo todo o seu poder de sedução com o objetivo de satisfazer o seu próprio desejo, assumindo o papel de sujeito na relação amorosa. 
No Livro de Sóror Saudade, percebemos uma espécie de diálogo com a obra de Sóror Mariana Alcoforado: o título remete à imagem de uma religiosa, a qual, no entanto, metamorfoseiase a cada aparição, oscilando entre a dor, o recolhimento, a renúncia, a atração pela morte e ainda o desejo, a insurreição e a revolta. Apesar de vestir o burel, o eu lírico, em momentos em que é guiado pelo ímpeto de alcançar a livre expressão de sua feminilidade, rompe o claustro e o sentimento erótico manifesta-se numa envolvente volúpia. É o que observamos, por exemplo, no soneto a seguir:

\section{Horas rubras}

Horas profundas, lentas e caladas Feitas de beijos sensuais e ardentes, De noites de volúpia, noites quentes Onde há risos de virgens desmaiadas...

Oiço as olaias rindo desgrenhadas...

Tombam astros em fogo, astros dementes,

E do luar os beijos languescentes São pedaços de prata p'las estradas...

Os meus lábios são brancos como lagos... Os meus braços são leves como afagos, Vestiu-os o luar de sedas puras...

Sou chama e neve branca e misteriosa...

E sou, talvez, na noite voluptuosa,

Ó meu Poeta, o beijo que procuras!

$$
\text { (ESPANCA, 1999, p. 196) }{ }^{4} \text {. }
$$

4 Todos os poemas de Florbela Espanca citados neste artigo se encontram no livro Poemas Florbela Espanca. Estudo introdutório, organização e notas de Maria Lúcia Dal Farra. São Paulo: Martins Fontes,1999. As citações dos poemas serão, portanto, seguidas apenas da página. 
A ardência amorosa presente já no título marca claramente também os versos iniciais: "Feitas de beijos sensuais e ardentes, / De noites de volúpia, noites quentes". A explosão de volúpia supera os limites do corpo e parece envolver todo o universo num gozo incontido: "Oiço as olaias rindo desgrenhadas... / Tombam astros em fogo, astros dementes, / $\mathrm{E}$ do luar os beijos languescentes / São pedaços de prata p'las estradas...". O apelo sinestésico traça uma sedutora trajetória do título ao último verso: tato, audição, visão, paladar, enfim, é preciso amar com todos os sentidos. É preciso a entrega e a posse total. Entretanto, não há uma concretização da união com o amado, o que resultaria na satisfação do desejo. Desse modo, o desejo continua a se alimentar de si próprio e a consumação do ato sexual mantém-se em suspenso.

A trajetória erótica da poesia de Florbela Espanca atinge o ápice em Charneca em flor. Todo o desejo de amar e ser amada, de possuir e ser possuída manifesta-se com força, com ardência e total volúpia. A sensualidade presente nos versos de Charneca em flor vai muito além do que permite a moral da época, principalmente em se tratando de uma obra de autoria feminina. Poemas como "Volúpia" que, como sugere o próprio título, privilegia um erotismo vivo, pulsante e perigoso, associando um prazer perverso a uma falsa e sedutora fragilidade, trazem à tona uma mulher que é senhora de si, do seu próprio corpo e emprega todos os artifícios do jogo erótico na sedução daquele que constitui o objeto do seu desejo. 


\section{Volúpia}

No divino impudor da mocidade,

Nesse êxtase pagão que vence a sorte,

Num frêmito vibrante de ansiedade,

Dou-te o meu corpo prometido à morte!

A sombra entre a mentira e a verdade...

A nuvem que arrastou o vento norte...

- Meu corpo! Trago nele um vinho forte:

Meus beijos de volúpia e de maldade!

Trago dálias vermelhas no regaço...

São os dedos do sol quando te abraço,

Cravados no teu peito como lanças!

E do meu corpo os leves arabescos

Vão te envolvendo em círculos dantescos

Felinamente, em voluptuosas danças...

O vinho, essência embriagante a habitar o corpo feminino, remete-nos às festas em homenagem a Baco: "- Meu corpo! Trago nele um vinho forte". O caráter pagão da metáfora do vinho se entrelaça com o aspecto divino do "corpo prometido à morte": "No divino impudor da mocidade, / Nesse êxtase pagão que vence a sorte, / Num frêmito vibrante de ansiedade, / Dou-te o meu corpo prometido à morte!". Mas o 
eu lírico transgride o destino que o conduz à eterna frieza e entrega-se ao prazer, arrastando consigo o homem que deseja: "Trago dálias vermelhas no regaço... / São os dedos do sol quando te abraço, / Cravados no teu peito como lanças! / E do meu corpo os leves arabescos / Vão te envolvendo em círculos dantescos / Felinamente, em voluptuosas danças...".

A presença da sinestesia é muito forte nesse soneto (a exemplo de outros poemas da autora), articulada de forma a acentuar o erotismo. A metáfora do vinho, os beijos "de volúpia e de maldade", as "dálias vermelhas", misto de pureza e de pecado, de fragilidade e de poder, cravando-se no peito do amado como raios de sol a envolvê-lo na ardência da paixão são apenas alguns exemplos desse recurso.

O poema é marcado pela expressão do desejo feminino, num movimento de sedução envolvente e perigoso cujo clímax, anunciado pelos tercetos, mantém-se em suspenso pela presença das reticências, o que revela o caráter sugestivo tão próprio do erotismo de Florbela Espanca.

"Volúpia", ao lado de outros sonetos de Charneca em flor, expressa uma dupla transgressão. Primeiro, pelo simples fato de abordar o erotismo. Depois, por revelar um questionamento da condição da mulher, inscrevendo-se como sujeito na relação amorosa, construindo uma identidade feminina que assume seu desejo e desafia as convenções. 


\section{AdíLIA Lopes: "Poetisa-FÊmeA"}

Embora sejam muitas as conquistas femininas das quais desfrutam as mulheres na atualidade, não podemos ignorar o fato de que ainda vivemos numa sociedade dominada pelo poder masculino que tenta relegar as mulheres ao silêncio e à marginalidade. No campo literário, essa realidade não é menos cruel, de modo que a voz de nossas escritoras não ressoa com a mesma liberdade nem recebe os mesmos aplausos reservados aos autores do sexo "dominante". É esse o cenário com o qual se depara a obra de Adília Lopes.

Dotada de uma visão crítica sobre a sociedade em que se insere, Adília Lopes, em poemas como o "Poetisa-fêmea, Poeta-macho (cliché em papel couché)" 5 , localizado no livro $A$ mulher-a-dias (2002), expõe a repartição dos papéis sociais atribuídos ao homem e à mulher na sociedade contemporânea. Como observa Sónia Rita C. Melo (2013, p. 134), "[A] dicotomia poetisa-fêmea / poeta-macho e os atributos respetivamente [sic] atribuídos a cada figura encerram claramente clichés, preconceitos, construções culturais e representações identitárias vinculados à hegemonia ideológica patriarcal."

5 Adília Lopes opta por adotar o termo "poetisa". Ao empregar o vocábulo feminino, a escritora afirma-se primeiramente como mulher, desafiando um sistema linguístico moldado pelo poder patriarcal. 


\section{POETISA-FÊMEA, POETA-MACHO ${ }^{6}$}

(cliché em papel couché)

1

Eu estou nua

eu estou viva

eu sou eu

Eu uso gravata

e, olhe, não foi barata

2

Sou uma poetisa-fêmea

falo do falo

Sou um poeta-macho sacho

3

Sou um poeta-macho

sou um desmancha-prazeres

sou um empata-fodas

Sou uma poetisa-fêmea

para mim

é tudo bestial

6 O título está em caixa alta, reproduzindo a forma adotada por Adília Lopes. 
4

Sou um poeta-macho

sou arrogante

sou um pé de Dante

Sou um poeta-macho

sou um facto

sou um fato

5

Sou um poeta-macho

tenho um gabinete

sou uma poetisa-fêmea

escrevo na retrete

Sou um poeta-macho

sou um badalo

sou uma poetisa-fêmea

calo-me

6

A poetisa-fêmea

toca viola

o poeta-macho

viola-a 


\section{7}

Senhora doutora, os seus seios

são feios

o poeta-macho

assina o despacho

8

Não tenho culpa

não tenho desculpa

não tenho custo

não tenho tempo

9

Natália Correia, Mário Soares

antes me ponha

um cacto

mas não me mato. (LOPES, 2014, p. 460-461)7.

A primeira estrofe constrói-se com uma evidente ênfase na autoafirmação do sujeito feminino que se "desnuda" diante do leitor, construindo uma identidade em tudo oposta a do ser masculino: "1 / Eu estou nua / eu estou viva / eu sou eu / [...]".

$\mathrm{O}$ uso reiterado das formas pronominais e verbais em primeira pessoa passa a impressão de que o poema constitui-se como uma espécie de diálogo em que o sujeito masculino e o

7 Todos os poemas de Adília citados neste trabalho encontram-se no livro Dobra: poesia reunida 1983-2014. Lisboa: Assírio \& Alvim, 2014. Citaremos, portanto, apenas o título do poema (quando houver) e a página. 
sujeito feminino buscam apresentar sua autodefinição. No entanto, é a visão feminina que prevalece a cada apresentação, expondo um conceito negativo no tocante ao "poeta-macho". Afinal, este é um "[...] arrogante / [...] um pé de Dante", um ser preso às convenções, cuja identidade está limitada à aparência, à superficialidade: "Eu uso gravata / e, olhe, não foi barata // [...] // Sou um poeta-macho / sou um facto / sou um fato".

Ao abordar a diferença entre o poeta-macho e a poetisa-fêmea, Adília Lopes coloca em evidência os desafios que se impõem à mulher. A quinta estrofe, por exemplo, denuncia o silêncio e a marginalidade a que é condenado o discurso feminino: "Sou um poeta-macho / sou um badalo / Sou uma poetisa-fêmea / Calo-me". Enquanto o poeta-macho tem um gabinete, a poetisa-fêmea escreve na retrete. Ecoa nessa ideia, a lição de Virgínia Woolf (Um teto todo seu, 1994) ${ }^{8}$ de que a mulher necessita de um espaço seu para poder exercer sua produção literária. Podemos ainda inferir que o fato de escrever na retrete significa expor o mais íntimo e até mesmo a imundície (o lixo) do ser, o que acentua o caráter transgressor da poesia feminina. Aliás, a ousadia da voz da poetisa já marca presença nos versos anteriores: "2 / Sou uma poetisa-fêmea / falo do falo / [...] // 3 / Sou um poeta-macho / sou um desmancha-prazeres / sou um empata-fodas // Sou uma poetisa-fêmea para mim / É tudo bestial".

$\mathrm{Na}$ sexta estrofe é dada maior ênfase ao poder opressor da sociedade misógina: "6 / A poetisa-fêmea / toca viola // o poeta-macho / viola-a". A violação vai além do aspecto pura-

8 A lição wolfiana é evidente, por exemplo, nos seguintes versos de um poema sem título gravado no Florbela Espanca espanca (1999): "1 Para escrever / é preciso / ter pouco / que fazer / [...] / Para escrever / é preciso / dinheiro.” (p. 390-391). 
mente sexual, podendo referir-se à usurpação do direito à livre expressão do ser feminino, inclusive no tocante ao desejo que habita o seu corpo.

O estilo "enviesado" de Adília Lopes normalmente rompe as expectativas do leitor. É o que observamos nas últimas estrofes, nas quais o sujeito feminino parece dar por encerrado o diálogo com o que consideramos uma simulação da voz masculina e, numa aparente falta de lógica, vai despachando versos que, a princípio, não se harmonizam com o restante do poema. No entanto, as linhas finais ("[...] / antes me ponha / um cacto / mas não me mato.") reafirmam a força, a entrega, a ousadia e o desejo de viver do ser feminino expressos na primeira estrofe.

Definindo-se como poetisa, assumindo e vincando, portanto, a autoria feminina, Adília "mostra-se consciente do esquecimento e da marginalização a que foram votadas as escritoras da história em geral e da história literária em particular." (MELO, 2015, p. 44). Desse modo, a poetisa posiciona-se contra o silenciamento literário imposto às escritoras, bem como em oposição às diversas formas de poder estabelecido sobre a muIher durante toda uma tradição. Na letra de Adília, emerge a identidade de uma mulher-sujeito dotada de mais liberdade de expressão e ação. 


\section{A questão do feminino nas obras de Florbela Espanca e Adília Lopes}

Inseridas em períodos histórico-literários diferentes, a produção poética de Florbela Espanca e de Adília Lopes apresenta características bem distintas. No entanto, observamos a existência de um diálogo produtivo entre a poética das duas escritoras, especialmente em razão do questionamento da condição historicamente imposta à mulher pela sociedade patriarcal.

São dois os livros em que observamos o diálogo com a poetisa alentejana: Clube da poetisa morta (1997) e Florbela Espanca espanca (1999). Em tais obras, a construção do sujeito feminino é um dos principais elementos que suscitam reflexões sobre como Adília Lopes dialoga com a poesia da autora de Charneca em Flor. No universo feminino construído pelos poemas de Florbela Espanca, deparamo-nos ora com imagens de mulheres marcadas pela contenção do desejo, ora com figuras sedutoras, repletas de volúpia, senhoras do próprio corpo. Na poesia de Adília Lopes, as imagens femininas e a temática do desejo também são constantes. No entanto, a linguagem é mais direta e as referências ao sexo são explícitas e, por vezes, expressas numa linguagem que pode ser considerada vulgar.

Em Clube da poetisa morta (1997), a ideia da contenção do desejo deve-se à frustrante ausência de um parceiro e à impossibilidade do ser feminino enquadrar-se no modelo de mulher desejável, bem como no papel submisso não só ao poder do homem como também da sociedade que impõe padrões de beleza, moda e consumo. 
Em meio a um elenco constituído por seres femininos desde poetisas (Florbela Espanca, Fiama Hasse Pais Brandão, Clarice Lispector, Mariana Alcoforado e a própria Adília Lopes) a figuras bíblicas, históricas ou míticas (Eva, Marta, Maria, Joana D'Arc, Medusa etc.), ou ainda ícones da moda, do mundo televisivo, da música e do cinema (Sylvie Vartan, Francoise Hardy e Mary Poppins, por exemplo), além de muIheres comuns (inspiradas nos contatos pessoais da autora ou simplesmente fruto da ficção) - o leitor depara-se com um sujeito feminino que se expressa em primeira pessoa e destoa do modelo de mulher há pouco referido. Essa incompatibilidade ${ }^{9}$ é manifesta em versos como os do poema "Preocupação com os meus cabelos": "Cobras em vez de cabelos / afugentam os meus pretendentes / Quem me dera ter os cabelos lisos / e usar franja / como a Sylvie Vartan / e a Françoise Hardy / [...]" (p. 301).

No poema "Meteorológica", identificamos a presença de um ser feminino superior, que comunica o seu desejo de forma clara. No entanto, a expressão do desejo de amor e de sexo faz-se acompanhada da ausência, da não realização, marcada por uma evidente frustração.

9 A incompatibilidade com o modelo de corpo desejável imposto pela sociedade pode ser notada de forma ainda mais contundente em "Body art?" (p. 338-339), do livro Sete rios entre campos, de 1999. 


\section{METEOROLÓGICA}

Deus não me deu

um namorado

deu-me

o martírio branco

de não o ter

Vi namorados

possíveis

foram bois

foram porcos

e eu palácios

e pérolas

Não me queres

nunca me quiseste

(porquê, meu Deus?)
A vida
é livro
e o livro

não é livre

Choro

chove

mas isto é

Verlaine 
Ou:

um dia

tão bonito

e eu

não fornico

Em Florbela Espanca espanca (1999), o elenco feminino não é menos variado que na obra anterior: a poetisa (Florbela Espanca, Mariana Alcoforado e Adília Lopes), a pintora, figuras comuns (a ceifeira, a trapezista, a mulher-a-dias etc.), personagens do mundo das artes (Alice, as Flamengas de Brel), a mãe, as fariseias, Maria Carolina e Maria Luísa, a Madalena célebre, Eva, Rosa Alice, Marianna, Maria Aliete Galhoz, Camila, Jénia, dona Rosinha, Maria Arminda e muitas outras.

O primeiro poema desse livro descreve um sujeito feminino que declara de forma bastante explícita o seu desejo sexual, derrubando quaisquer limites impostos às mulheres, a começar pelas barreiras morais. É nesse tom de ousadia que Adília Lopes declara:

Eu quero foder foder

achadamente

se esta revolução

não me deixa

foder até morrer

é porque

não é revolução 
nenhuma

a revolução

não se faz

nas praças

nem nos palácios

(essa é a revolução

dos fariseus)

a revolução

faz-se na casa de banho

da casa

da escola

do trabalho

a relação entre

as pessoas

deve ser uma troca

hoje é uma relação de poder

(mesmo no foder)

a ceifeira ceifa

contente

ceifa nos tempos livres

(semana de $24 \times 7$ horas já!)

a gestora avalia

a empresa

pela casa de banho

e canta

contente

porque há alegria

no trabalho

o choro da bebé 
não impede a mãe de se vir a galinha brinca com a raposa eu tenho o direito de estar triste

O poema é construído num evidente diálogo com Florbela Espanca, numa "relação dúbia de homenagem e provocação" (MENEZES, 2011, p. 49) comumente observada na convocação de outros nomes da literatura para a composição da obra adiliana.

O texto de Adília Lopes retoma especificamente o soneto "Amar!", presente em Charneca em Flor, cujos versos transcrevemos a seguir:

\section{Amar!}

Eu quero amar, amar perdidamente!

Amar só por amar: aqui... além...

Mais Este e Aquele, o Outro e toda a gente...

Amar! Amar! E não amar ninguém!

Recordar? Esquecer? Indiferente!...

Prender ou desprender? É mal? É bem?

Quem disser que se pode amar alguém

Durante a vida inteira é porque mente! 
Há uma primavera em cada vida:

É preciso cantá-la assim florida,

Pois se Deus nos deu voz, foi pra cantar!

E se um dia hei-de ser pó, cinza e nada

Que seja a minha noite uma alvorada,

Que me saiba perder... pra me encontrar...

(p. 134)

Embora no poema de Florbela Espanca o amor possa assumir sentidos outros que não o que envolve a relação sexual e ainda que tomado nesse sentido a união não se realize efetivamente, no contexto do início do século $X X$, os versos desse soneto constituem uma evidente provocação aos valores morais que imperam em Portugal. Neles identificamos um sujeito feminino que deseja "amar perdidamente", ignorando as convenções e expressando livremente a sua insaciabilidade, pois que seu amor não é direcionado a um único ser, além de ultrapassar todos os limites uma vez que deseja "Amar só por amar: aqui... além...". Esse sentimento é dirigido a "Este e Aquele, o Outro e toda a gente..." e, ao mesmo tempo, há o anseio de "Amar! Amar! E não amar ninguém!".

A autoafirmação do sujeito feminino enquanto ser livre, insubmisso prossegue de forma evidente na segunda estrofe. Há uma negação da ideia do sofrimento amoroso ("Recordar? Esquecer? Indiferente!....), da fidelidade que aprisiona ("Prender ou desprender? É mal? É bem?") e mesmo do amor eterno ("Quem disser que se pode amar alguém / Durante a vida inteira é porque mente!") tão comumente imputados à mulher. 
Ressoa nas últimas estrofes o tema do carpe diem, num convite ao desfrute dos prazeres que a vida pode oferecer: "Há uma primavera em cada vida: / É preciso cantá-la assim florida, / Pois se Deus nos deu voz, foi pra cantar!" - com um toque da soturnidade florbeliana: "E se um dia hei-de ser pó, cinza e nada", logo convertida na ideia de encontro consigo mesma, de plenitude do ser: "Que seja a minha noite uma alvorada, / Que me saiba perder... pra me encontrar...”.

É curioso notar que, décadas depois, o aspecto insurrecto do poema seja potencializado na grafia de Adília Lopes. Conforme observa Raquel Góes de Menezes (2011, p. 51), "foi possível à Adília apresentar o desejo florbeliano mais explicitamente ao substituir 'amar' por 'foder', mantendo apenas um dos sentidos de 'amor' e carregando-o de carga exclusivamente sexual". No entanto, o caráter transgressor que o poema de Adília Lopes assume não se limita ao fato de tomar o sentido do termo "amar" apenas em seu aspecto sexual. A transgressão consiste especialmente em trabalhar o sentido de "revolução" como algo que, além de compreender o aspecto político, envolve a vida privada das pessoas, das mulheres em particular. A revolução pela qual anseia o ser mulher é antes uma revolução no cotidiano, na intimidade, uma revolução do corpo, uma revolução sexual.

Logo no início do poema de Adília Lopes, é evidente o tom provocativo marcado pelo riso e pelo escárnio, comumente presentes no aparato poético da autora: "Eu quero foder foder / achadamente". E a provocação segue no questionamento implícito sobre o sentido da revolução: "se esta revolução / não me deixa / foder até morrer / é porque / não é revolução 
/ nenhuma". A liberdade que o ser lírico almeja diz respeito à livre expressão da sua sexualidade, ao direito de dispor do próprio corpo conforme a sua vontade. A ideia construída pelo poema é de que a revolução não ocorre exclusivamente no espaço público, uma vez que ela "não se faz / nas praças / nem nos palácios", pois "(essa é a revolução / dos fariseus)". É no campo privado, nas relações interpessoais, no cotidiano pessoal, familiar e profissional que se abalam as antigas estruturas que impõem limites à liberdade do ser feminino. Assim, "a revolução / faz-se na casa de banho / da casa / da escola / do trabalho".

O poema discute claramente "a relação entre / as pessoas", no sentido de que essa "deve ser uma troca". Mas constata que "hoje é uma relação de poder / (mesmo no foder)". Tal constatação, associada à ideia do histórico papel relegado ao sexo feminino, assume caráter de denúncia contra a exploração da mulher em sua condição de objeto sexual. Os versos seguintes apresentam figuras femininas que subvertem essa lógica e afirmam-se como sujeito, sendo senhoras do próprio desejo, ainda que exerçam também atividades no trabalho ou no lar: "a ceifeira ceifa / contente / ceifa nos tempos livres / [...] / a gestora avalia / a empresa / pela casa de banho / e canta / contente/ [...] o choro da bebé / não impede a mãe / de se vir".

Mesmo os versos "a galinha brinca/ com a raposa" - que nos remete a um efeito constante nos poemas de Adília: a quebra de expectativa do leitor - podem comparecer gratuitamente ou, sem destoarem do restante do poema, sinalizarem a ousadia do ser que desafia o convencional, que assume riscos. Um ser feminino complexo que derruba barreiras afirmando a sua força, mas que também pode simplesmente declarar: "eu tenho o direito / de estar triste". 
REVISTA CRIOULA N ${ }^{\circ} 20-2^{\circ}$ SEMESTRE $/ 2017$

\section{Considerações finaIS}

Num contexto em que ainda são negados à mulher direitos básicos como o da educação, a obra (assim como a vida ${ }^{10}$ ) de Florbela Espanca não atende fielmente às exigências dos padrões impostos pela sociedade portuguesa das primeiras décadas do século $\mathrm{XX}$, adepta de uma rígida moral religiosa cristã, que exige da mulher um papel de ser passivo e recatado, submisso ao poder masculino.

Exprimindo uma voz de mulher que rompe com os padrões ditados ao sexo feminino, por colocar em evidência o seu modo de pensar e de sentir, inclusive o seu desejo sexual, os poemas de Florbela Espanca realizam uma verdadeira subversão do papel destinado à mulher. $\mathrm{O}$ caráter subversivo no tocante ao papel feminino marca também os versos da escritora contemporânea Adília Lopes, como procuramos demonstrar na análise de alguns de seus poemas, dentre os quais destacamos o que mais evidencia o diálogo com a autora de Charneca em flor.

A leitura que empreendemos da produção poética de Adília Lopes, especialmente o Florbela Espanca espanca, identifica como característica acentuada a preocupação em abater valores de uma sociedade marcada por preconceitos de toda ordem (especialmente em relação à mulher), pelo consumismo, pela sede de poder; indiferente a questões como a tolerância, o respeito e o amor.

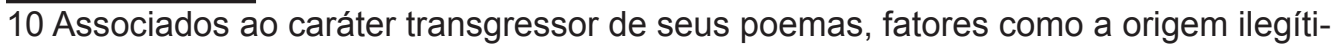
ma, o elevado nível cultural, a ousadia de divorciar-se e de buscar novos amores e a escolha de abdicar da própria vida são alguns pontos da biografia de Florbela Espanca que desafiam as convenções morais e religiosas de Portugal, interferindo significativamente na recepção crítica da produção florbeliana. 
O procedimento de Adília Lopes parece-nos, de certa forma, uma opção política, na medida em que traz para a sua poesia um elenco diverso de figuras femininas, permitindo a essas a expressão de seus desejos, de suas insatisfações. Adília Lopes, assim como Florbela Espanca, dá voz a um sujeito feminino que questiona a sua condição de mulher. Ela põe em cheque a história única contada pelo ser masculino ao lançar luz sobre a história lida e escrita por mulheres.

\section{REFERÊNCIAS BIBLIOGRÁFICAS}

COELHO, Nelly Novaes. O corpo-da-escrita no romance feminino português. In: Literatura e diferença. IV Congresso Abralic. Anais. São Paulo, 1994. p. 817-823.

ESPANCA, Florbela. Poemas de Florbela Espanca. 2.ed. São Paulo: Martins Fontes, 1999.

LOPES. Adília. Dobra: poesia reunida 1983-2014. 2.ed. Lisboa: Assírio \& Alvim, 2014.

MELO, Sónia Rita C. . Adília Lopes ou a impessoalidade da terceira mulher. In: Ex aequo, Vila Franca de Xira, n. 27, p. 129-141, 2013 . Disponível em: http://www.scielo.mec.pt/ scielo.php?script=sci_arttext\&pid=S0874-556020130001000 09\&lng=pt\&nrm=iso. Acesso em: 08 jan. 2017.

. Des-dobra: re-visão e tradução. A construção da poesia em Adília Lopes. 2015. 449 f. Tese (Doutorado em Filolo- 
gia) - Universidade de Barcelona. Barcelona, 2015. Disponível em: http://diposit.ub.edu/dspace/bitstream/2445/66446/1/ SRCM_TE SE.pdf. Acesso em: 21 dez. 2016.

MENEZES, Raquel Góes. O projeto literário Adília Lopes. 2011. 117 f. Dissertação (Mestrado em Letras) - Faculdade de Letras - Universidade Federal do Rio de Janeiro, 2011. Disponível em: http://www.letras.ufrj.br/posverna/mestrado/ MenezesRG.pdf. Acesso em: 02 dez. 2016.

SILVESTRE, Osvaldo. Adília Lopes espanca Florbela Espanca. Texto lido no lançamento de Florbela Espanca espanca. Companhia de Teatro Sensurround, Lisboa, 11 mar. 2000. Disponível em: <http://arlindo-correia.com/adilia_lopes1.html>. Acesso em: 02 fev. 2013.

WOOLF, Virginia. Um teto todo seu. 10.ed. Trad. Vera Ribeiro. Círculo do Livro: São Paulo, 1994.

Submissão: 01/08/2017

Aceite: $12 / 11 / 2017$ 